\title{
OPEN Social signaling via bioluminescent blinks determines nearest neighbor distance in schools of flashlight fish Anomalops katoptron
}

\author{
Peter Jägers ${ }^{1}$, Louisa Wagner ${ }^{1}$, Robin Schütz ${ }^{1}$, Maximilian Mucke ${ }^{1}$, Budiono Senen ${ }^{2}$, \\ Gino V. Limmon ${ }^{3,4}$, Stefan Herlitze ${ }^{1 \bowtie}$ \& Jens Hellinger ${ }^{1}$
}

The schooling flashlight fish Anomalops katoptron can be found at dark nights at the water surface in the Indo-Pacific. Schools are characterized by bioluminescent blink patterns of sub-ocular light organs densely-packed with bioluminescent, symbiotic bacteria. Here we analyzed how blink patterns of A. katoptron are used in social interactions. We demonstrate that isolated specimen of $A$. katoptron showed a high motivation to align with fixed or moving artificial light organs in an experimental tank. This intraspecific recognition of $A$. katoptron is mediated by blinking light and not the body shape. In addition, $A$. katoptron adjusts its blinking frequencies according to the light intensities. LED pulse frequencies determine the swimming speed and the blink frequency response of $A$. katoptron, which is modified by light organ occlusion and not exposure. In the natural environment $A$. katoptron is changing its blink frequencies and nearest neighbor distance in a context specific manner. Blink frequencies are also modified by changes in the occlusion time and are increased from day to night and during avoidance behavior, while group cohesion is higher with increasing blink frequencies. Our results suggest that specific blink patterns in schooling flashlight fish $A$. katoptron define nearest neighbor distance and determine intraspecific communication.

Bioluminescence is a widespread phenomenon in ocean-dwelling organisms including a broad phylogenetic distribution in marine fish ${ }^{1}$. Fish represent the only class of vertebrates which developed the ability to emit bioluminescent light. Light is emitted via own photophores, bioluminescent bacteria hosted within specialized light organs or kleptoproteins acquired from prey $^{2}$. In ray finned fish bioluminescence evolved independently at least 27 times $^{3}$.

Numerous functions of bioluminescence have been described and suggested such as counterillumination ${ }^{4,5}$, mate attraction $^{6}$, prey attraction ${ }^{7}$ and prey illumination in flashlight fish (Anomalopidae) ${ }^{8}$. All members of the family Anomalopidae such as Photoblepharon and Anomalops are characterized by bean-shaped, subocular light organs $\mathrm{s}^{9,10}$. In Photoblepharon steinitzi three distinct functions in bioluminescent signaling like finding prey, intraspecific communication and confusing predators via a "blink and run-pattern" have been proposed ${ }^{11,12}$. Photoblepharon reside solitary- or pairwise in territories (e.g. reef caves) while Anomalops katoptron (Anomalopidae) occur in large, moving schools during moonless nights ${ }^{8,13}$.

The extrinsic, continuous bioluminescent light in A. katoptron is produced by symbiotic bioluminescent bacteria Candidatus photodesmus katoptron (Gammaproteobacteria: Vibrionaceae) hosted within subocular light organs. Anomalopid symbionts show a genome reduction like other unrelated, obligate symbiotic bacteria, such as insect endosymbionts. It has been proposed that symbionts of A. katoptron are transmitted during an active environmental phase ${ }^{14-16}$. Symbiotic bacteria are densely packed in numerous tubules that are aligned at right angles to the light-emitting surface of light organs ${ }^{8,16,17}$. The inner surface of light organs contains two stacks of guanine crystals, which serve as reflector to enhance light emission ${ }^{18}$. At the anterior edge light organs are attached to suborbital cavities via the rod like "Ligament of Diogenes" which allows a downward rotation. This exposes the dark pigmented back of light organs and disrupts light output. The visual system of $A$. katoptron is

\footnotetext{
${ }^{1}$ Department of General Zoology and Neurobiology, Institute of Biology and Biotechnology, Ruhr-University Bochum, 44780 Bochum, Germany. ${ }^{2}$ Fisheries College Hatta-Syahrir, Banda Naira, Malukuh Tengah, Indonesia. ${ }^{3}$ Department of Aquatic Resources Management, Faculty of Fisheries and Marine Science, Pattimura University, Ambon, Indonesia. ${ }^{4}$ Maritime and Marine Science Center for Excellence, Pattimura University, Ambon, Indonesia. ${ }^{\square}$ email: sxh106@gmail.com
} 
optimized to detect wavelengths in the frequency range of its own bioluminescent symbionts ${ }^{19,20}$. Fascinating blink patterns of large schools can be observed on coral reefs in the Indo-Pacific during dark and moonless nights ${ }^{13,21}$. During the daytime A. katoptron hides in crevices, caves or deep water ${ }^{8,21}$.

In general, groups of fish show various formations ranging from lose aggregations to highly aligned groups moving in synchronized directions ${ }^{22,23}$. Living in a group can be advantageous in several aspects like lower predation risk, mate choice ${ }^{24}$, reduced metabolic $\operatorname{costs}^{25}$ and higher probability in detecting food sources ${ }^{26}$. It has been proposed that a synchronized organization within the school leads to lower vulnerability ${ }^{27}$. Group size and cohesion play an important role in schooling and can reduce the risks of being preyed through attack abatement ${ }^{28}$ or confusion of predators ${ }^{29}$.

The ability to sense intraspecific group members is important to maintain the formation of a school ${ }^{30}$. Sensory input from vision and lateral lines are integrated to determine attraction or repulsion in moving groups. Partridge \& Pitcher suggested that vision is primarily used for maintenance of position and angle between fish while lateral lines monitor swimming speed and direction of moving neighbors ${ }^{31}$. The school formation is situation-dependent and can be interpreted as an integration of surrounding ecological factors. For example higher predation regimes force shoaling groups of Poecilia reticulata (Poecillidae) to form denser aggregations with closer nearest neighbor distance $^{27,32}$. Collective behavior has been recently analyzed with computer models and/or robotic dummies revealing strong correlation between decision rules of individuals driving group behavior ${ }^{13,33-36}$.

Providing information to conspecifics is an important feature to maintain the functionality of a dynamic group and can be observed on inter-individual and/or group level ${ }^{35}$. Many different ways of intraspecific communication are described within fish just as mutual allocation in the weakly electric fish Mormyrus rume proboscirostris (Mormyridae) via electrocommunication that leads to social attention ${ }^{37}$ or startle response as a reaction on moving neighbors in Clupea harengus (Clupeidae) ${ }^{38}$.

As nocturnal animals live under visual restriction, bioluminescent signaling can become an additional source of information ${ }^{7}$ e.g. in orientation towards conspecifics shown in ostracodes (Cypridinidae) ${ }^{39,40}$ dragonfish (Stomiidae) $^{41,42}$ or pony fish (Leiognathidae) ${ }^{43}$. For Gazza minuta (Leiognathidae) discrete projected luminescent flashes have been described. Possible functions are spacing between foraging individuals, keeping the school together or reproductive activities each represented in different flash patterns ${ }^{44}$.

It has been shown that $A$. katoptron uses its light organs to actively localize food. During feeding the light organs reveal a prolonged exposure and shorter occlusion time resulting in decreased blink frequencies ${ }^{8}$. In addition, it has been described that the light organs play a role in orientation towards conspecifics and synchronization of swimming dynamics in schooling behavior of A. katoptron ${ }^{13}$.

In this study we investigated how A. katoptron behaviorally responds to different artificial light stimuli and if these behavioral responses can be compared to a context-dependent blinking behavior observed in the natural environment at the Banda Sea (Indonesia). We found that A. katoptron is attracted by blue/green light in a blink frequency and light intensity dependent manner. The fish responds with an adjustment of its own blink frequencies, where the light organ occlusion, but not the exposure time is adjusted. Higher blink frequencies are correlated with closer nearest neighbor distance leading to a higher group cohesion. Thus, our study shows for the first time that the blink frequencies of the bioluminescent light of the flashlight fish $A$. katoptron determines nearest neighbor distance in a context dependent, intraspecific behavior.

\section{Results}

To investigate how bioluminescent signaling emitted by the light organs of the splitfin flashlight fish Anomalops katoptron is used for intraspecific communication, we investigated the behavioral responses of isolated flashlight fish to artificial light pulses in the laboratory. It has been shown that A. katoptron in its natural environment reveal a schooling behavior ${ }^{13}$. To investigate if and how A. katoptron reacts to different light signals we isolated A. katoptron in an experimental tank (Fig. 1a,b). In the middle of the tank we introduced a light emitting dummy and defined two areas, where we analyzed the duration of how long the fish spend in this area, i.e. one area close to the dummy (center area) and one area close to the exit area (exit door) of the tank. This exit door is normally open and connects the experimental tank with the housing tank. Without light stimulation individuals stayed for $64.4 \pm 5.7 \%$ (Fig. 1a,c) of the time in the exit area compared to the center area. Fish were swimming with a swimming speed of $0.19 \pm 0.01 \mathrm{~m} / \mathrm{s}$ (Fig. 1d). Stimulation with artificial light organs caused an orientation towards the fish dummy (Fig. 1b). Isolated specimen spent $79.7 \pm 3.9 \%$ of the time in the center around the light emitting dummy (LED timing: $2 \mathrm{~Hz}, 0.25 \mathrm{~s}$ on $+0.25 \mathrm{~s}$ off) and reduced their swimming speed. (Fig. 1c,d, Video S1).

Control experiments showed that the shape of the dummy does not have an impact on the behavior of $A$. katoptron (Fig. S1). These findings suggest that light pulses are used for intraspecific communication of $A$. katoptron and that A. katoptron is attracted by these light pulses (Fig. 1).

To investigate if the light intensity of light pulses plays a role for intraspecific communication, we determined the emitted light intensity of A. katoptron's light organs. Light emitted by luminous bacteria housed within the light organs of $A$. katoptron had an intensity $\geq 0.24 \mu \mathrm{W}$ in the frequency range between $498-522 \mathrm{~nm}$ wavelengths at intensities larger than $90 \%\left(\lambda_{\max }\right.$ at $510 \mathrm{~nm}, \mathrm{n}=5$; Fig. S2). We next applied LED light stimuli $(1 \mathrm{~Hz}, 0.5 \mathrm{~s}$ on $+0.5 \mathrm{~s}$ off) with light intensities of $0.12,0.33$ and $1.52 \mu \mathrm{W}$ (at $504 \mathrm{~nm}$ wavelength) and found that increasing light intensities resulted in decreased blink frequencies. There were no differences in distances kept to the dummy (around $15.67 \pm 0,64 \mathrm{~cm}$ ). Thus, throughout the experiments we used a LED light, with an intensity at $504 \mathrm{~nm}$ wavelength of $0.23 \mu \mathrm{W}$ (except for the intensity experiments), which is slightly dimmer than the light emitted from the light organ of $A$. katoptron.

To investigate if the blink frequency is important for intraspecific communication, we presented three different blink frequencies $(0.5 \mathrm{~Hz} ; 1 \mathrm{~Hz} \& 2 \mathrm{~Hz})$ with equally distributed LED light on- and off-times (Fig. 1c-f). While there was no difference in time spent in the center area (Fig. 1c), there was a frequency-dependent change 

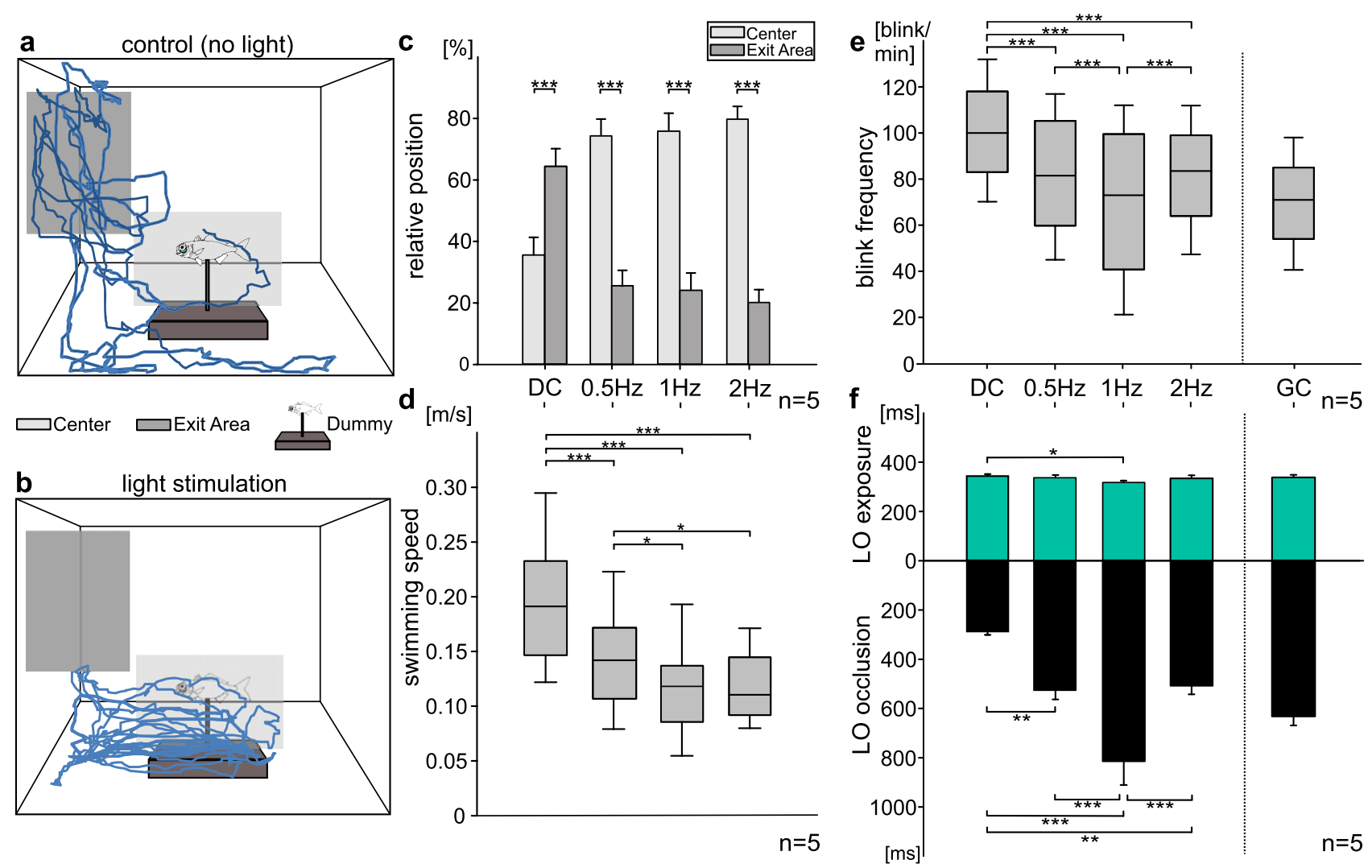
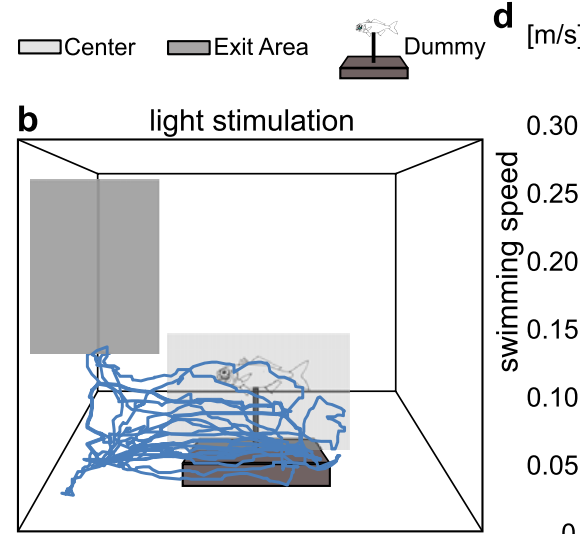

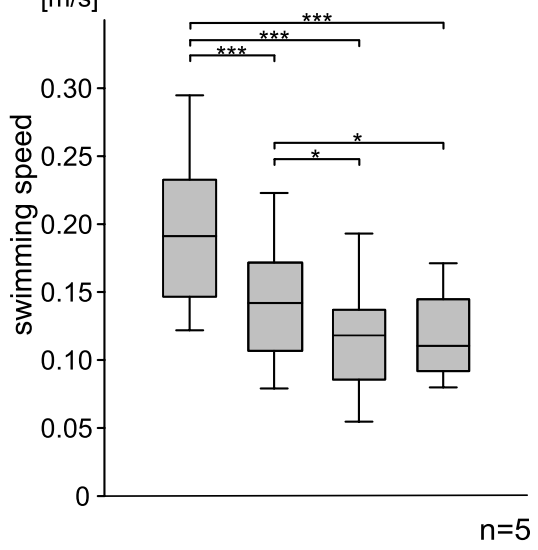

$[\mathrm{ms}$

Figure 1. Frequency-dependent light stimuli transmitted by artificial light organs mediate changes in positioning, swimming speed, blink frequency and light organ occlusion of $A$. katoptron. (a,b) Example trajectories of A. katoptron (60 s) without (a) and with (b) a $1 \mathrm{~Hz}$ light stimulation of the fish dummy. (c) Relative positioning in exit or center area of isolated $A$. katoptron during different light stimuli (DC; $0.5,1$, $2 \mathrm{~Hz})(\mathrm{n}=5)$. (d) Swimming speed of isolated A. katoptron during different light stimuli (DC; 0.5, 1, $2 \mathrm{~Hz})$ $(\mathrm{n}=5)$. (e) Blink frequencies of isolated A. katoptron induced by different light stimuli (DC; 0.5, 1, $2 \mathrm{~Hz})$ (left) in comparision to blink frequencies detected in a small group of five individuals in the reef tank (GC) (right) $(\mathrm{n}=5)$. (f) Mean light organ exposure and occlusion times during different light stimuli (DC, 0.5, 1, $2 \mathrm{~Hz}$ ) (left) in comparision to exposure and occlusion times measured in a small group of five individuals in the reef tank (GC) (right) $(\mathrm{n}=5)$. Figures were created with SigmaPlot 12.0 (www.sigmaplot.co.uk) and processed with CorelDraw Graphics Suite 2017 (www.coreldraw.com). DC, dark control; GC, group control. Significance values are reported as ${ }^{\star} p<0.05,{ }^{* *} p<0.01,{ }^{* *} p<0.001$. Error bars indicate \pm SEM.

in swimming speed (Fig. 1d), the blink frequency response (Fig. 1e) along with the exposure and occlusion of the light organs (Fig. 1f). A light stimulation of $0.5 \mathrm{~Hz}$ resulted in a swimming speed of $0.146 \pm 0.009 \mathrm{~m} / \mathrm{s}$, which is faster than the swimming speed determined for $1 \mathrm{~Hz}$ and $2 \mathrm{~Hz}$ stimulation $(1 \mathrm{~Hz}(0.115 \pm 0.008 \mathrm{~m} / \mathrm{s}), 2 \mathrm{~Hz}$ $(0.119 \pm 0.006 \mathrm{~m} / \mathrm{s})$, RM ANOVA $0.5 \mathrm{~Hz}$ compared to: $1 \mathrm{~Hz}, p=0.014 ; 2 \mathrm{~Hz}, p=0.023$; Fig. $1 \mathrm{~d})$.

We next analyzed the blink frequency responses of $A$. katoptron. We found that during schooling behavior in the tank the average blink frequency of individuals was $1.17 \mathrm{~Hz}(69.88 \pm 1.78 \mathrm{blinks} / \mathrm{min})$, while in isolation the blink frequency is increased to $1.67 \mathrm{~Hz}(100.39 \pm 1.83$ blinks/min $)$. At $1 \mathrm{~Hz}$ LED light stimulation, the blink frequency of $A$. katoptron was $70.25 \pm 2.72 \mathrm{blinks} / \mathrm{min}$ and was comparable to the blink frequency within the school (i.e. $1.17 \mathrm{~Hz}$ ), but is increased to $1.35 \mathrm{~Hz}$ for $0.5 \mathrm{~Hz}$ and $2 \mathrm{~Hz}$ light stimulation.

Next we investigated mean light organ exposure and occlusion for the different experimental light pulse settings. We found that the time individuals expose light organs is around $330 \mathrm{~ms}$, which was comparable throughout the experiments (DC $(344 \pm 0.005 \mathrm{~ms}), 0.5 \mathrm{~Hz}(338 \pm 0.004 \mathrm{~ms}), 1 \mathrm{~Hz}(317 \pm 0.006 \mathrm{~ms}), 2 \mathrm{~Hz}(336 \pm 0.008 \mathrm{~ms})$; Fig. 1f). In contrast, differences existed in how long the organ is occluded. We found that in isolation the fish decreases its occlusion time to $287 \pm 0.01 \mathrm{~ms}$, while during schooling $(618 \pm 0.069 \mathrm{~ms})$ and in the presence of the light stimuli, light organ occlusion increased $(0.5 \mathrm{~Hz}(528 \pm 0.035 \mathrm{~ms}), 1 \mathrm{~Hz}(967 \pm 0.092 \mathrm{~ms}), 2 \mathrm{~Hz}$ $(0.507 \pm 0.036 \mathrm{~ms})$; Fig. 1f $)$. These findings suggest that light organ occlusion defines blink frequencies during schooling.

Thus, the findings on blink frequencies related to light organ occlusion, orientation and swimming speed led us to the hypothesis that the timing of light pulses emitted by A. katoptron bear information to keep attraction and alignment of $A$. katoptron to its conspecifics.

To investigate this hypothesis, we established a second experimental setup in a circular arena tank, with a light pulse emitting dummy in the middle of the arena (Fig. 2a). We changed the LED off-times between 200 and $500 \mathrm{~ms}$ with on-times at $300 \mathrm{~ms}$ and examined the distance of the individuals towards the artificial light organs of the dummy in the center using heat maps. Without light stimulation individuals were swimming 
a

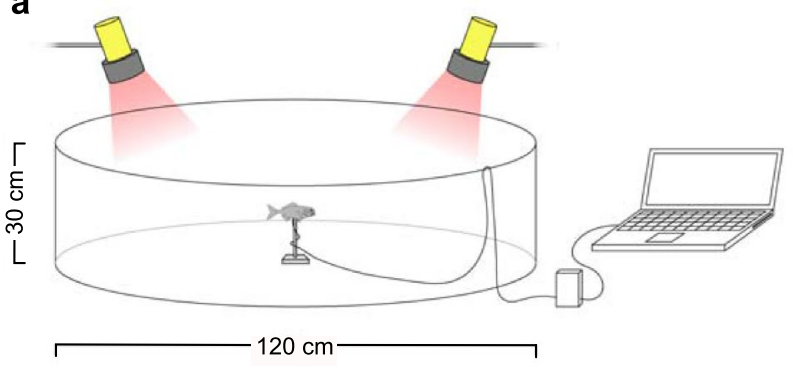

b

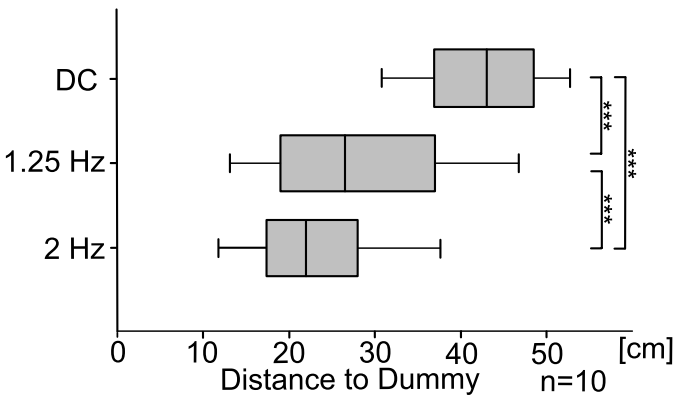

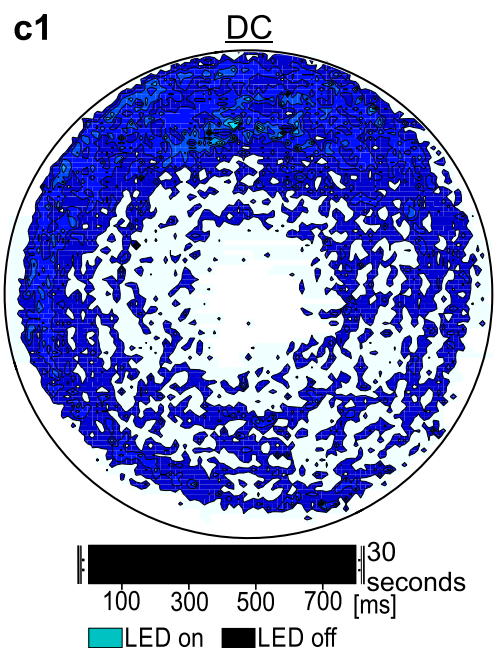
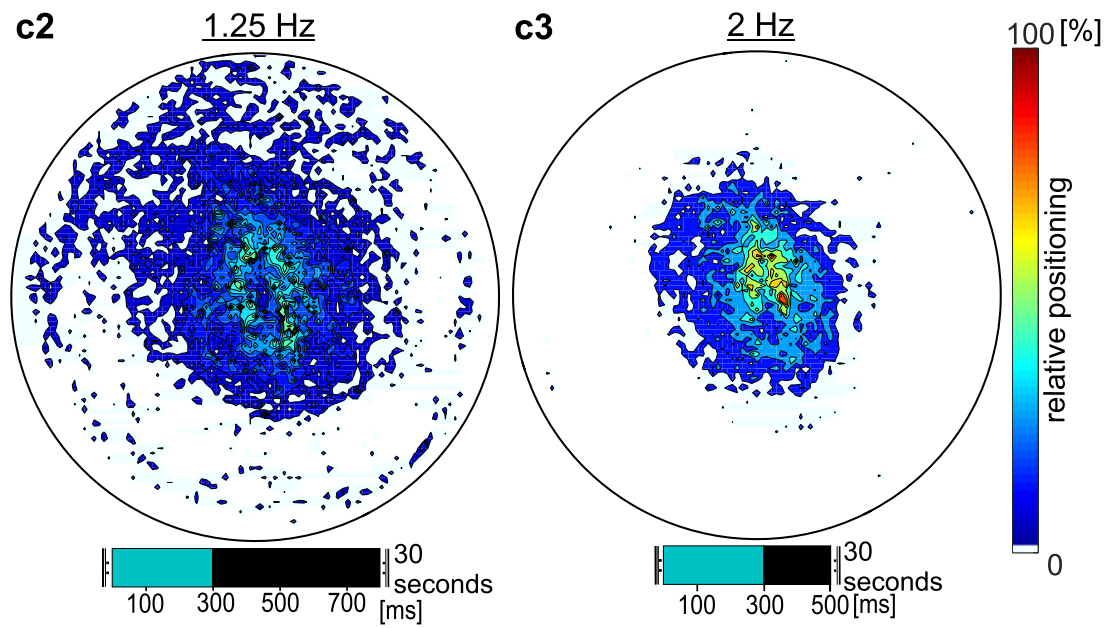

Figure 2. Frequency-dependent light stimuli transmitted by artificial light organs determine nearest neighbor distance of A. katoptron. (a) Experimental setup for the validation of changes in nearest neighbor distance.

Artificial light organs of a center placed dummy were emitting different light stimulations. (b) Average distance between A. katoptron and the fish dummy equipped with artificial light organs $(n=10)$. (c) Heat Maps indicate positioning of $A$. katoptron in relation to no light (c1) or light $(\mathbf{c} 2, \mathbf{c} 3)$ emitting dummy. Heat Maps are based on all trajectories recorded for each stimulation $(n=10)$. Figures were created with SigmaPlot 12.0 (www.sigmaplot. co.uk) and processed with CorelDraw Graphics Suite 2017 (www.coreldraw.com). DC, dark control. Significance values are reported as: ${ }^{\star} p<0.05,{ }^{* *} p<0.01,{ }^{* * *} p<0.001$.

along the wall and avoiding the middle of the arena (Fig. 2c1) with a mean distance of $42.25 \pm 0.76 \mathrm{~cm}$ to the dummy (Fig. 2b). During light stimulation A. katoptron changed its swimming behavior in an off-time dependent manner (Fig. 2c2-3). A $500 \mathrm{~ms}$ LED off-time resulted in a closer but still partly decentralized orientation $(23.63 \pm 0.88 \mathrm{~cm})$ towards the dummy in comparison to the dark control (DC; RM ANOVA: $p<0.001$, Fig. 2c2; Video S2). The closest and centralized orientation towards the LED dummy occurred with $200 \mathrm{~ms}$ off-time LED stimulation (Fig. 2c3). These findings suggest that light organ occlusion contains information about nearest neighbor distance for A. katoptron.

In the ocean, schools of $A$. katoptron constantly move through the open water, suggesting that individuals recognize/monitor their nearest neighbor to stay aligned. Thus, we next examined if $A$. katoptron would follow a moving light signal. To perform this experiment, we used an experimental setup, in which 13 LEDs arranged in a circular swimming tank separated by an angle of $27.7^{\circ}$ lit up for $300 \mathrm{~ms}$ consecutively clockwise or counterclockwise (Fig. 3a, S3 and Video S3).

Isolated specimens were following the counter- or clockwise rotating LED light to $75 \%$ of the time without showing off-time-dependency (Fig. S3). A higher swimming speed of A. katoptron was observed for the $200 \mathrm{~ms}$ off-times $(0.285 \pm 0.013 \mathrm{~m} / \mathrm{s})$, representing faster moving LEDs, in comparison to the $500 \mathrm{~ms}$ off-times $(0.246 \pm 0.007 \mathrm{~m} / \mathrm{s})$ and the control without light stimulation (DC; $0.213 \pm 0.008 \mathrm{~m} / \mathrm{s})$ (Fig. $3 \mathrm{~b}$ ). In contrast, the fish follows the rotating LEDs at $500 \mathrm{~ms}$ off-times closer and with higher precision $(1.25 \mathrm{~Hz} ; 0.771 \pm 0.013$; Fig. 3c,d2) in comparison to $200 \mathrm{~ms}$ off-times $(2 \mathrm{~Hz}$; $0.63 \pm 0.023$; Fig. $3 \mathrm{c}, \mathrm{d} 3)$ and control (DC; $0.365 \pm 0.013$; Fig. $3 \mathrm{c}, \mathrm{d} 1)$. The results suggest that $A$. katoptron lose precision to follow artificial light organs at higher swimming speeds.

We next investigated the blinking behavior of several schools of $A$. katoptron in the ocean at a cave near Ambon and on a reef flat of Banda Island, Maluku, Indonesia. During the day the school of A. katoptron could be observed within the cave, while at sunset the school left the cave to approach the reef flat. We also observed a context dependent blink behavior and distinguished three different behavioral conditions, i.e. blinking behavior in the cave during the day, blinking behavior at the reef flat during the night and blinking behavior during avoidance triggered by a red diving torch. As also observed in the aquarium, blink frequencies increased from $1.96 \mathrm{~Hz}$ (cave, $117.69 \pm 1.55 \mathrm{blink} / \mathrm{min}$, Video S4), $3.33 \mathrm{~Hz}$ (reef flat, $199.71 \pm 3.21 \mathrm{blink} / \mathrm{min}$, Video S5) 


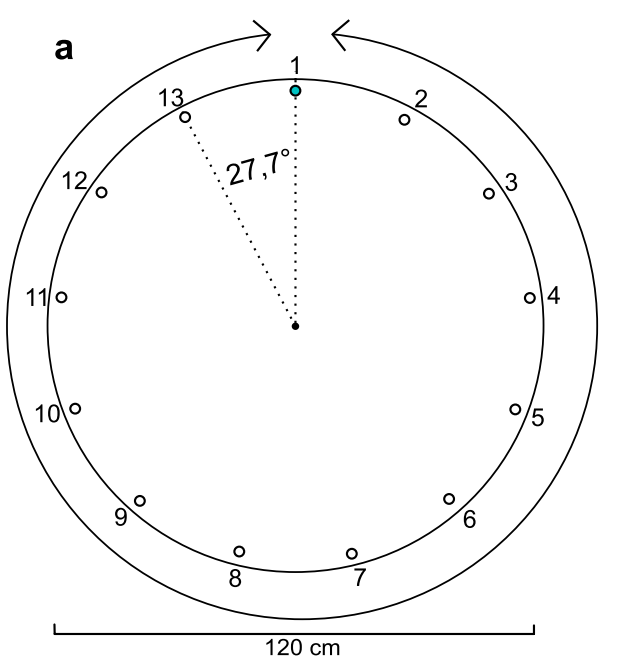

b

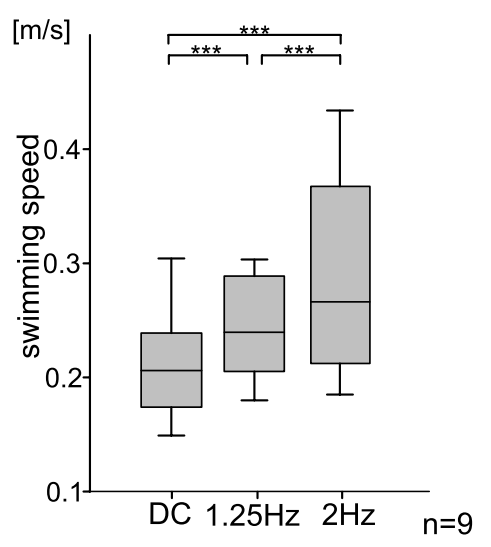

c

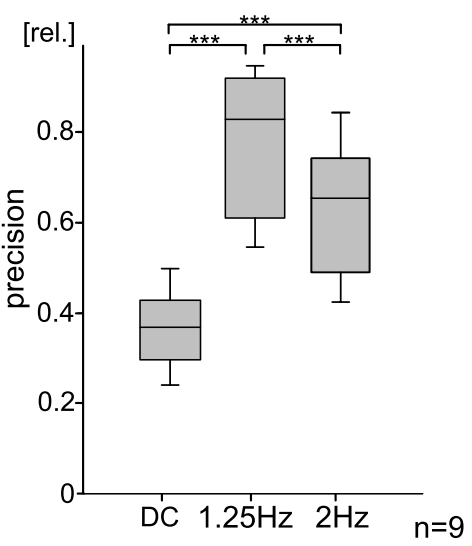

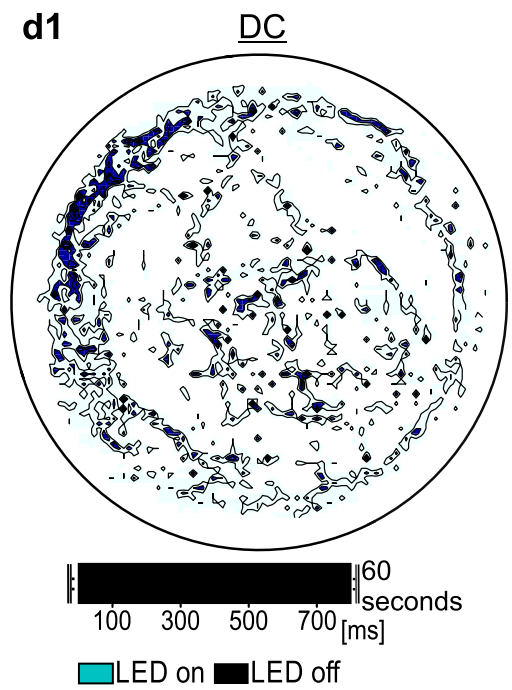

d2
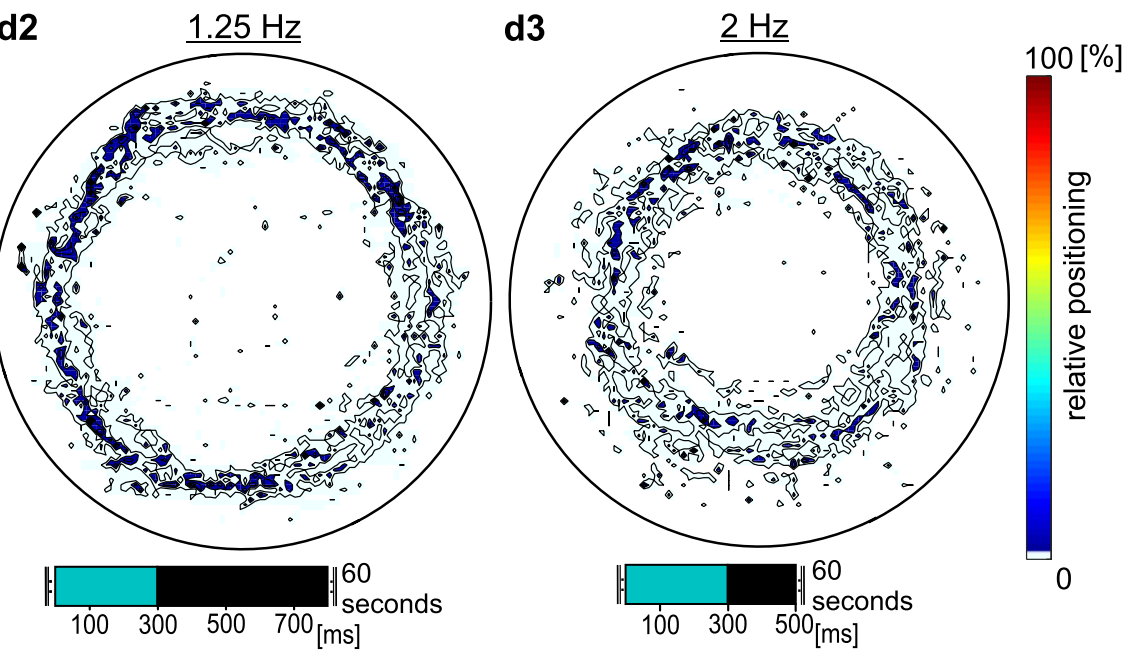

Figure 3. Anomalops katoptron are motivated to follow a moving light source. (a) Experimental setup with 13 wall mounted LEDs that were triggered consecutively counter- or clockwise with different frequencies. (b) Mean swimming speed of isolated $A$. katoptron during no light (DC) and light stimulation $(1.25 \mathrm{and} 2 \mathrm{~Hz})(\mathrm{n}=9)$. (c) Relative distance between $A$. katoptron and the center of the tank according to the motivation of individuals to follow the moving light source $(\mathrm{n}=9)$. (d) Heat Maps indicate positioning of $A$. katoptron during no light (d1) or light stimulation $(\mathbf{d} 2, \mathbf{d} 3)(n=9)$. Each heat map shows the average of five trials for one isolated specimen. Figures were created with SigmaPlot 12.0 (www.sigmaplot.co.uk) and processed with CorelDraw Graphics Suite 2017 (www.coreldraw.com). DC, dark control; ${ }^{\star} p<0.05,{ }^{* *} p<0.01,{ }^{* * *} p<0.001$.

to $3.97 \mathrm{~Hz}$ (avoidance, 238.45 $\pm 4.79 \mathrm{blink} / \mathrm{min}$, Video S6, Fig. 4a) with light organ occlusion ranging from $347.14 \pm 10.8 \mathrm{~ms}$ (cave), $120.66 \pm 2.39 \mathrm{~ms}$ (reef flat) to $68.65 \pm 2.34 \mathrm{~ms}$ (avoidance, RM ANOVA: $p<0,001$ ), while light organ exposure remained constant at around $230 \mathrm{~ms}$ (cave $=229.91 \pm 3.05 \mathrm{~ms}$, reef flat $=219.63 \pm 4.79 \mathrm{~ms}$, avoidance $=233.89 \pm 6.53 \mathrm{~ms}$, Fig. $4 \mathrm{~b}$ ). In addition, we found that the variation in blink frequencies is highest during avoidance behavior (Gaussian distribution; $X\left(\mu=3.97 \mathrm{~Hz} ; \sigma^{2}=3.062 \mathrm{~Hz}\right)$ ) and low during daytime, while hiding in the caves (Gaussian distribution; X $\left(\mu=1.96 \mathrm{~Hz} ; \sigma^{2}=0.476 \mathrm{~Hz}\right)$ ) (Fig. 4c). During avoidance behavior the relative nearest neighbor distance is reduced compared to reef flat schooling behavior from $2.03 \pm 0.169 \mathrm{SL}$ $(\mathrm{n}=37)$ to $1.42 \pm 0.09 \mathrm{SL}(\mathrm{n}=46)$ and an increased group cohesion becomes obvious in the synchronized escape movements (Fig. 4d).

\section{Discussion}

In this study we found that variation in blink frequencies of the bioluminescent splitfin flashlight fish Anomalops katoptron is used for intraspecific communication important for schooling behavior. In particular, we demonstrate that blink frequencies are adjusted by variations in the occlusion time of the light organ and that blink frequencies determine nearest neighbor distance.

Schools of A. katoptron can be observed at dark and moonless nights at the water surface in the Indo-Pacific. A. katoptron emit short bioluminescent light pulses using specialized light organs situated under the eye during schooling ${ }^{8,13}$. These subocular light organs are densely packed with bioluminescent, symbiotic bacteria (Candidatus photodesmus katoptron), which continuously produce bioluminescent light ${ }^{14-16}$. The fish disrupts light emission by a downward rotation of the light organ. Thus, exposure and occlusion of the light organ can produce 

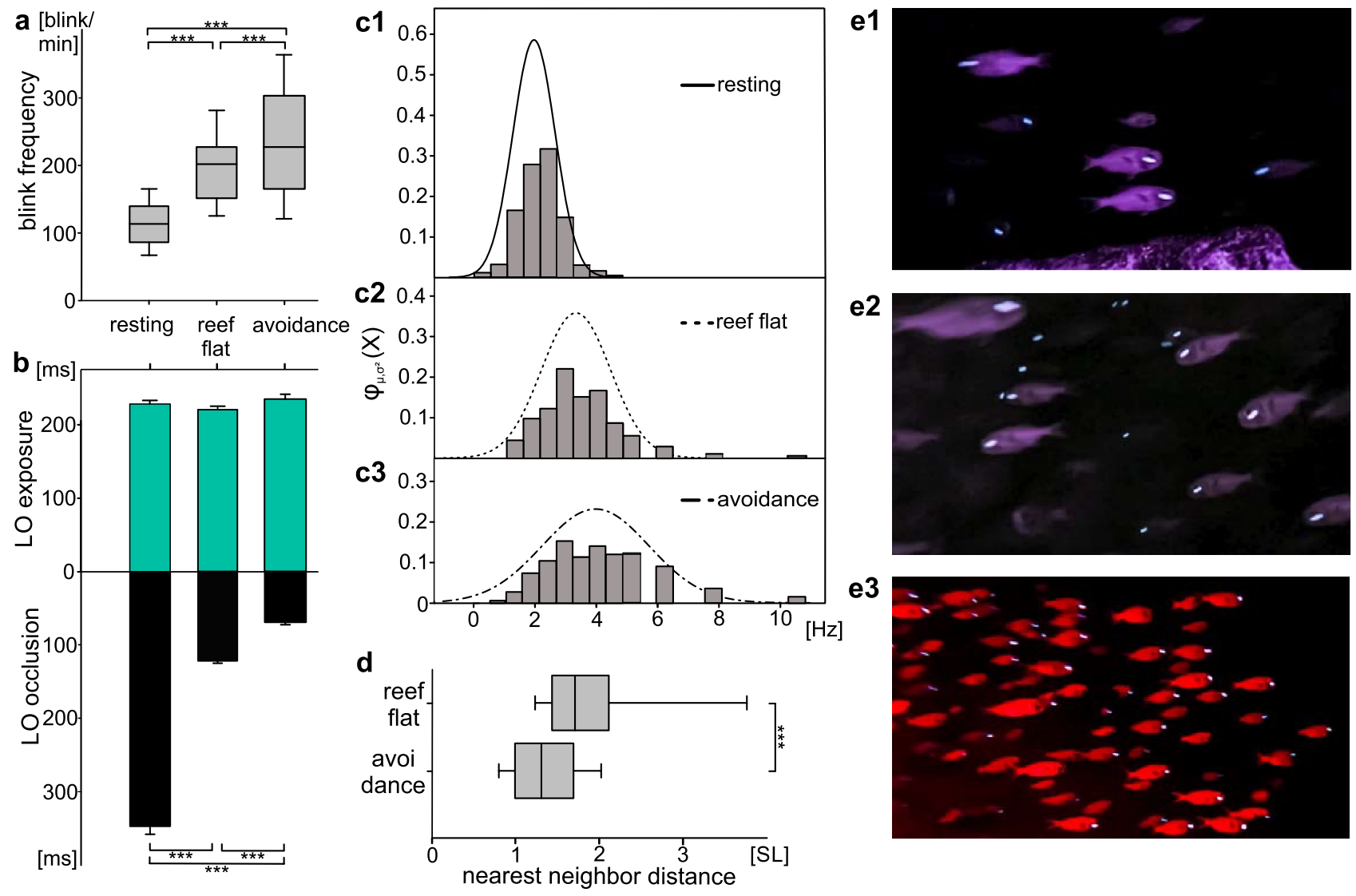

\section{e3}

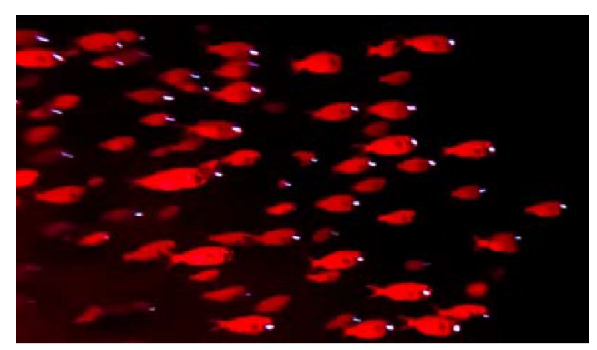

Figure 4. Analysis of the blinking behavior and nearest neighbor distance of schools of A. katoptron in Ambon, Maluku, Indonesia. (a) Analysis of blink frequencies of $A$. katoptron in the cave, at the reef flat and during avoidance. Blink frequencies were calculated by analyzing alternating light organ exposure and occlusion (cave $\mathrm{n}=709$; reef flat $\mathrm{n}=444$ and avoidance $\mathrm{n}=478$ ). (b) Mean light organ exposure and occlusion of $A$. katoptron in the cave (open $n=823$; closed $n=761$ ), at the reef flat (open $n=502$; closed $n=445$ ) and during avoidance (open $n=516$; closed $n=478$ ). Upper lines refer to stimulation as seen in (a). (c) Relative distribution of blink frequencies of $A$. katoptron observed while resting in the cave (c1), at the reef flat (c2) and during avoidance (c3). Bars represent histogram with bin size of $0.6 \mathrm{~Hz}$. Distribution was fitted with a normal (Gaussian) distribution. (d) Analysis of the nearest neighbor distance of $A$. katoptron on the reef flat $(\mathrm{n}=37)$ and during avoidance $(\mathrm{n}=46)$. Nearest neighbor distance is given as standard length (SL). (e) Example still images of the videos of A. katoptron schooling during day in the cave (e1), during the night on the reef flat (e2) and during avoidance behavior in the night (e3). Figures were created with SigmaPlot 12.0 (www.sigmaplot.co.uk) and processed with CorelDraw Graphics Suite 2017 (www.coreldraw.com). Significance values are reported as: ${ }^{\star} p<0.05,{ }^{* *} p<0.01,{ }^{* *} p<0.001$. Error bars indicate \pm SEM.

specific blink frequencies ${ }^{45}$. We found that adjustment of the blink frequencies of $A$. katoptron depends on variations within the occlusion and not the exposure of the light organ while schooling, which we demonstrated in the experimental tank and in the native environment. Light organ exposure is comparable to previous laboratory $\left(383 \mathrm{~ms} ;{ }^{8}\right)$ and field $\left(166 \mathrm{~ms} ;{ }^{13}\right)$ studies. In comparison longer flash durations of $400 \mathrm{~ms}$ in Lampanyctus niger ${ }^{42}$ and 1000-2000 ms in Gazza minuta ${ }^{44}$ have been described in other bioluminescent fish.

Intraspecific recognition/communication is important to establish and maintain group structures ${ }^{46}$. Speciesspecific signals like visual cues ${ }^{30,47}$, motion ${ }^{48}$, auditory ${ }^{49}$ or electric signal ${ }^{37}$ have been described to be involved in this process. Visual cues are important to detect position and movement of conspecifics ${ }^{31}$ or predators ${ }^{50}$ in fish and become crucial in species that live under dim/low light conditions such as A. katoptron ${ }^{7,51}$. The bioluminescent light of $A$. katoptron is used for actively finding food and is most likely important for schooling behavior under dim light conditions and, therefore, for intraspecific communication ${ }^{8,13}$. Gruber et. al (2019) used video recording sequences of schools of $A$. katoptron and computer simulations to demonstrate that flashlight fishes use bioluminescent blinks to school at night. Schooling is stable when only a few percent of fish flash their bioluminescent light organs and a change in direction of only a few fish can change the swimming direction of the entire school ${ }^{8,13}$.

In our study we showed that A. katoptron follows moving LED light pulses and that the swimming speed is adjusted to the moving light. The speed of the moving LEDs at $2 \mathrm{~Hz}$ potentially exceeded the mean swimming speeds of A. katoptron, since individuals could follow the moving LEDs at lower moving speed $(1.25 \mathrm{~Hz})$ more precisely. Mean swimming speeds depend on various factors such as body size, tail beat frequency, scale types 
or hydrodynamic effects ${ }^{52}$. The mean swimming speed of $A$. katoptron was estimated to 3,5 BL/s (body length per second), which correlates with other marine species ${ }^{24,53,54}$.

By analyzing the blinking behavior of A. katoptron we found that for intraspecific recognition A. katoptron only uses information of the blinking light and not the body shape, since we did not detect differences in the blink behavior when we used LEDs or LEDs implanted within a fish dummy.

In addition, we found that higher light intensities of the LEDs induced lower blink frequencies of A. katoptron. One possibility is that higher intensity light is causing stronger behavioral responses, because the higher intensity light penetrates further through water and could be received as a closer schooling neighbor. We measured for the first time the maximal light intensity of light emitted by the light organ from A. katoptron. The intensity spectrum reveals a broad peak around $90 \%$ of the maximal light intensity (i.e. $0.27 \mu \mathrm{W}$ ) from $498-522 \mathrm{~nm}$, which coincides with the action spectrum of the photoreceptors, as well as the retinal and behavioral responses of $A$. katoptron $^{19}$. Light intensity could potentially represent fitness levels of individuals as A. katoptron tend to loose luminescence due to starvation ${ }^{55}$. Other fish species prefer to shoal with healthy conspecifics ${ }^{56,57}$. Schooling fish tend to show consistency in their appearance (confusion effect) ${ }^{29,58}$ and often do not show a sexual dimorphism including flashlight fish (but also see pony fish Gazza minuta) ${ }^{44,59}$.

The most important result of our study is that blink frequencies adjusted by light organ occlusion determine nearest neighbor distance. We suggest that light organ exposure and occlusion are alternating signals for attraction and repulsion in defining nearest neighbor distance in schooling A. katoptron. Nearest neighbor distance is a key factor in schooling fish and determines group cohesion ${ }^{60}$. The shape of a school is the integration of individual responses on surrounding ecological factors ${ }^{46}$. Thereby intraspecific signals such as bioluminescent blinks in flashlight fish need to be included. This is also supported by the findings of Gruber et al. (2019) who show that schools of flashlight fish change direction, when a few fish speed up along a particular direction, while the rest of the school is following. Thus, flashing is needed to convey the directional changes within the school ${ }^{8,13}$. In ponyfish (Leiognathidae) luminescent flashes have been proposed to function in spacing between individuals and keeping the school together ${ }^{61}$. Here we present a mechanism that potentially drives the opposing forces of attraction and repulsion in bioluminescent fish.

To gain an understanding of how blinking behavior is used for intraspecific communication in the field, we analyzed the blinking behavior of schools of A. katoptron in a cave during the day and at the entrance of the cave during the night in Ambon, Malukku, Indonesia using infrared recordings. This allowed us visualize the entire fish to correlate the changes in blink frequencies with the nearest neighbor distance, school formation and cohesion. We found that the blink frequency decreased during the day in comparison to blink behavior at night. Blinking behavior increased when fish were illuminated with a red torch, which caused an avoidance behavior and a reduction in the nearest neighbor distance. This became obvious by a change from a broad to a dense school formation. Avoidance behavior may reflect a blink and run pattern as has been suggested ${ }^{11,13}$. Increased blink frequencies seem to be correlated with stress reactions, since we observed increased blink frequencies when A. katoptron were isolated in the laboratory. Increase in blink frequencies are also known from Photoblepharon steinitzii, when artificial intruders have been introduced into their territory ${ }^{12}$.

In conclusion, our study shows that Anomalops katoptron uses intraspecific, bioluminescent blink signals for communication of nearest neighbor distance important for group cohesion during schooling.

\section{Methods}

Recordings in the laboratory. Maintenance of A. katoptron. A group of splitfin flashlight fish A. katoptron was kept in a reef tank $(600 \mathrm{l} ; 135 \mathrm{~cm}$ length $\times 66 \mathrm{~cm}$ depth $\times 70 \mathrm{~cm}$ height). All specimens were obtained from a commercial wholesaler (De Jong Marinelife, Netherlands) and captured at the Cebu Islands (Philippines). For at least six weeks prior to the experiments A. katoptron were kept in the reef tank (temperature: $26^{\circ}-27^{\circ} \mathrm{C}$; salinity: $36 \%$; $12 \mathrm{~h}$ day and night cycle). The housing tank $(600 \mathrm{l} ; 135 \mathrm{~cm}$ length $\times 66 \mathrm{~cm}$ depth $\times 70 \mathrm{~cm}$ height $)$ was connected to an additional filter sump containing phosphate absorber, activated carbon, protein skimmer and an UV-sterilizer. The specimens were fed once a day with defrosted zooplankton (mysid shrimps), fish/lobster eggs and fine minced, defrosted salmon. Feeding occurs under dim red light to obtain visual observation on fitness levels of individuals. Information on age is missing because all individuals were wild collected imports. No visible differences between females and males were observed and therefore we cannot associate sex specific blinking patterns. Individuals were identified by size, slight differences in pigmentation and intensity of light organs.

Artificial light organs and fish dummies. A fish dummy with artificial light organs was made of black silicon (food safe silicon MM720 FG; Silikonfabrik; Germany). The shape of the dummy was modelled based on several photographs and had a total length (TL) of $101 \mathrm{~mm}$. At the anterior-ventral side an oval shaped opening was cut out of the dummy. The cutout was equipped with a LED to imitate the light organs of $A$. katoptron. The LED was connected to an Arduino microcontroller (Arduino Mega 2560; Arduino; Italy). Resistors between LED and microcontroller were set to an output flow of $1 \mathrm{~mA}$. The LED was waterproof glued (2-K epoxy glue; UHU; Germany) in an acrylic glass tube (length $15 \mathrm{~mm}$; external diameter $7 \mathrm{~mm}$ ) painted with flat white acrylic paint (Revell; Germany) to diffuse the LED light. The acrylic glass inlet was mounted in the fish dummy (artificial light organ length: $10 \mathrm{~mm}$; height: $7 \mathrm{~mm}$ ). The LED (Nichia $3 \mathrm{~mm}$ LED cyan $14.720 \mathrm{mcd}$; Winger; Germany) had a peak wavelength at $504 \mathrm{~nm}$ and was adjusted to the mean light emittance of $0.23 \mu \mathrm{W} / \mathrm{nm}$ of $A$. katoptron's light organs (Fig. S2). Intensities of light organs $(n=5)$ and LEDs were measured with a spectrometer (Ocean Optics; Flame S-UV-VIS-ES; United States). Therefore, the spectroscopic probe was placed right angled in front of the light emitting surface of light organs of $A$. katoptron or artificial light organs. Average light intensities were calculated with a polynomial regression and weights computed from the Gaussian density function in SigmaPlot 12.0 (Fig. S2). 
The microcontroller was set to control artificial light organs in relation to on- and off-times. The control software was written with Matlab (Matlab 2015r) and the open source Arduino software (Arduino 1.8.10). LED light intensities were adjusted by using a pulse width modulation (PWM).

Recordings in the experimental tank and arena experiments (see below) were made with an infrared (IR) sensitive camcorder (Sony HDR-CX 730; $6.3 \mathrm{~mm}$ CMOS-Sensor, 24.1 megapixel, video resolution $1920 \times 1080$ pix, $50 \mathrm{fps}$ ) mounted on a custom made aluminum stand. Video files were converted to audio video interleave-format (.avi) with a resolution of $1080 \times 720$ pix and 25 fps using Adobe Premiere Elements 15 (Adobe; United States).

Blink frequencies (equal LED on- and off-times). The recording tank was divided in the middle with a grey PVC plate. Specimens could switch sides through a lockable slide door $(20 \times 20 \mathrm{~cm})$. One of the sides contained daytime shelters made from clay tiles whilst the other half was blank except for a flow pump (EcoDrift 4.2; Aqua Medic; Germany). Specimen of A. katoptron $(\mathrm{n}=5)$ were isolated on the blank side $(60 \mathrm{~cm} \times 60 \mathrm{~cm} \times 60 \mathrm{~cm})$ of the experimental tank and habituated for 5 min prior to the experiment.

The fish dummy was placed in the middle of the recording tank. Each light stimulus was presented for a duration of five minutes. Every stimulus presentation was repeated five times. Here we chose equal distributed on- and off times in LED timing with $0.5 \mathrm{~Hz}$ ( $1 \mathrm{~s}$ on- and $1 \mathrm{~s}$ off-time), $1 \mathrm{~Hz}(0.5 \mathrm{~s}$ on- and $0.5 \mathrm{~s}$ off-time) and $2 \mathrm{~Hz}(0.25 \mathrm{~s}$ on- and $0.25 \mathrm{~s}$ off-time). Previous laboratory experiments showed a nearly equal distribution of light organ exposure and occlusion times while swimming in a group ${ }^{8}$. We performed a control experiment with turned off artificial light organs (DC, dark control) implemented in the dummy. The camera was mounted on a tripod in front of the tank. Two IR-lights each consisting of five high power LEDs with $860 \mathrm{~nm}$ peak wavelength (WEPIR1-S1 IR Power $1 \mathrm{~W}$, Winger Electronics GmbH, Germany) were placed $10 \mathrm{~cm}$ above the tank.

In a second experiment, we analyzed the role of dummy (fish) shape and isolated light organ dummies on the behavior of $A$. katoptron ( $\mathrm{n}=5$; same individuals used in the first experiment). Therefore, an isolated light organ dummy (LED as described above) was used during stimulation. We chose a light stimulation protocol of $1 \mathrm{~Hz}$ ( $0.5 \mathrm{~s}$ on- and $0.5 \mathrm{~s}$ off-times) because this stimulation had the strongest effect on blink frequencies of isolated specimen. In the next step we analyzed differences in blink frequencies for two specimens with intact light organs as well as one specimen with intact and one with non-glowing light organs to test orientation of $A$. katoptron towards light organs of conspecifics (Fig. S1). In this case, we performed a frame by frame analysis (video analysis software; Vidana 1.0) of distances between individuals. All stimuli were presented for five minutes in a pseudo-randomized order. Five repetitions were performed for each specimen.

Blink frequencies (reported in blink/min) and light organ exposure -/occlusion-times (reported in ms) were analyzed frame by frame using Solomon Coder (Version 19.08.02). Mean values of blink frequencies and light organ exposure-/occlusion-times were analyzed with Excel (Excel 2016). Successive exposure and occlusion events were summarized as blink event.

Trajectories were analyzed with the video analysis software Vidana 1.0. Two rectangles of interest (ROI) were defined to analyze the swimming profiles in A. katoptron. As individuals could switch between the two sides of the tank amongst experiments, we defined the areas where occurrence was most likely. The area around the closed door was declared as "exit area". The area around the dummy placed in the middle was defined as "center".

Arena experiment 1: nearest neighbor distance. Large-scale swimming profiles during presentation of a fish dummy with artificial light organs were analyzed in a circular arena with $120 \mathrm{~cm}$ diameter (Winipet Dogpool; China). Seawater from the housing tank was used to ensure equal parameters in water chemistry e.g. carbon hardness, nitrate and $\mathrm{pH}$ values. The arena was filled with approximately 1701 seawater $(15 \mathrm{~cm}$ water level). Single specimen of $A$. katoptron $(\mathrm{n}=10)$ were transferred to the arena using a hand net $(12.5 \mathrm{~cm} \times 10 \mathrm{~cm}$; Sera; Germany). Prior to the experiments fish were habituated for five minutes in the arena tank. A fish dummy with artificial light organs (as described above) was placed $7.5 \mathrm{~cm}$ over the tank bottom in the center of the arena. In this experiment artificial light organs were constantly glowing up for $300 \mathrm{~ms}$ whereas off-times changed. The occlusion of artificial light organs was adjusted to $200 \mathrm{~ms}$ ( $2 \mathrm{~Hz}$ stimulation) or $500 \mathrm{~ms}$ (1.25 Hz stimulation) but consistent during one trial. We additionally performed a control experiment without light emitted by the dummy (DC, dark control). Stimuli were randomly presented for $30 \mathrm{~s}$ with six repetitions. Videos were recorded using an infrared (IR) sensitive Sony HDR-CX730E camcorder $(1920 \times 1080$ pix; $50 \mathrm{fps})$ mounted above the arena on a custom made stand. Two IR-lights each consisting of five high power LEDs (WEPIR1-S1 IR Power $1 \mathrm{~W}$, Winger Electronics GmbH, Germany) were placed besides the arena mounted on custom made holding devices. Tracking profiles of A. katoptron were analyzed using the video analysis software Vidana 1.0. Heat maps were generated in Matlab (Matlab R2015b). Here we summarized equal positions of standardized tracking profiles to estimate relative occurrences of $A$. katoptron.

Arena experiment 2: swimming speed. To validate the following behavior and maximum swimming speeds of A. katoptron we established an array of LEDs that were rotated consecutively to simulate a moving light organ. In this experiment, 13 LEDs were wall-mounted in an equal distributed distance (specifications circular arena see above). Angle between LEDs was set to $27.69^{\circ}$. The LEDs were placed on a water level of $7.5 \mathrm{~cm}$. On-times of LEDs was permanently set to $300 \mathrm{~ms}$ while interval among the light onset between two LEDs was changed. During one trial intervals between two LEDs were set to $200 \mathrm{~ms}$ or $500 \mathrm{~ms}$ (travelling speed of light: $200 \mathrm{~ms}$, $0.58 \mathrm{~m} / \mathrm{s} ; 500 \mathrm{~ms}, 0.36 \mathrm{~m} / \mathrm{s})$. LEDs were triggered clockwise or counter clockwise in a pseudo randomized order. A dark control (DC) experiment without light stimulation was performed to avoid potential orientation cues from the periphery of the experimental arena. Handling of A. katoptron as described under Arena Experiment 1.

Experiments in single specimens of A. katoptron $(\mathrm{n}=9)$ were started after five minutes habituation time in the arena. Each stimulus was presented for $60 \mathrm{~s}$. Specimens were tested five times for each stimulus. Movement 
profiles, swimming speed and radius of A. katoptron were analyzed using the video analysis software Vidana 1.0. Relative movement directions were estimated with Solomon Coder (Version 19.08.02). We estimated the precision of $A$. katoptron to follow moving light sources on a defined radius (distance between individuals and center of the tank). For each stimulation $(1.25 \mathrm{~Hz}, 2 \mathrm{~Hz} \& \mathrm{DC})$ we calculated the probability of individuals to move with the direction of light (Fig. S3). During dark control (DC) isolated individuals were moving clockwise $(0.41 \pm 0.034)$, counterclockwise $(0.44 \pm 0.034)$ or without a defined movement direction, declared as other $(0.15 \pm 0.001)$. Isolated specimen were following the counter- or clockwise rotating LED light to $0.724 \pm 0.034$ (200 ms off-times) and $0.78 \pm 0.031$ (500 ms off-times). Subsequently we multiplied the probability to follow the rotating light or the highest value in case of the dark control (DC) with the radius to estimate the precision.

Field recordings. Field recordings were made alongside two different Islands in the Banda Sea (Indonesia). Several schools of $A$. katoptron were observed via snorkeling on the shallow reef flats of Pulau Gunung Api, Banda Islands ( $\left.4^{\circ} 30^{\prime} 20.2^{\prime \prime S} 129^{\circ} 52^{\prime} 49.7^{\prime \prime E}\right)$. Recordings on the Banda Islands were made after sunset on 1st-4th of March 2019 prior new moon (7th of March 2019) and the 26th of March 2019 (five days after full moon). Recordings on the Banda Islands were made before moonrise. Schools of A. katoptron occur from deeper water ( $>60 \mathrm{~m}$; pers. obs.) or caves during dark and moonless nights on the shallow reef flats of Gunung Api. The observation site in Ambon ( $\left.3^{\circ} 44^{\prime} 54.5^{\prime \prime S} 128^{\circ} 12^{\prime} 43.3^{\prime \prime} \mathrm{E}\right)$ was quite different and recordings made while scuba diving. Schools were hiding throughout the day in a large cave (main chamber dimensions approximately $10 \times 5 \times 6 \mathrm{~m}$ ) with many small crevices that were not accessible. The cave entrance was in approximately $6 \mathrm{~m}$ depth beneath the water surface depending on the tide. Field recordings in Ambon were made between 19th-20th of March 2019 before full moon (21st of March) and on 17. April 2019 before full moon (19th of April 2019). During the day, recordings were made in the cave and continued while sunset when schools of A. katoptron emerged through the cave exit. After several minutes schools accumulated in front of the cave where overhanging rock casts a shadow of the moonlight. This was leading to a restricted area of movement. We defined three different recording conditions to analyze the behavior in A. katoptron: 1. "resting" (recordings in the cave during day without illumination); 2. "schooling" (outside cave or on reef flat during night without illumination) and 3. "avoidance" (avoidance elicited by red diving torch during night).

Video recordings were made with a modified camera (Canon Powershot G1X Mark 2; APS-C-Sensor; 24 megapixel; video resolution: $1920 \times 1080$ pix; $30 \mathrm{fps}$ ). The infrared filter in front of the camera sensor was removed to obtain infrared sensitivity. The camera was placed in an underwater housing (Canon WP-DC53). Two custom made underwater infrared lights mounted on both sides of the underwater housing were used two illuminate schools of A. katoptron in the cave and open water. Each IR-light consisted of five high power IR-LED with $860 \mathrm{~nm}$ peak wavelength (WEPIR1-S1 IR Power 1 W, Winger Electronics GmbH, Germany).

A LED diving torch with red light (300 lm red light; $634 \mathrm{~nm}$ peak wavelength; Codylight 1500; Codygear; Germany) was switched on while the school was swimming outside the cave or on the reef flat to elicit avoidance reactions. "Avoidance" was triggered pseudorandomized when specimen were within a range of approximately $1.5 \mathrm{~m}$ to ensure sufficient illumination with IR-lights. The red light was switched on until the school disappeared from view. After A. katoptron gathered outside the cave a minimum of two minutes was waited before red torches were repeatedly turned on.

We recorded $\mathrm{n}=5$ video sequences (709 blink events in $326 \mathrm{~s}$ ) for "resting" in the cave, $\mathrm{n}=8$ video sequences ( 444 blink events in $272 \mathrm{~s}$ ) during "schooling" on the reef flat and $\mathrm{n}=5$ video sequences ( 478 blink events in $40 \mathrm{~s}$ ) in case of "avoidance".

Relative distances between school members were estimated via ImageJ (ImageJ 1.50i; National Institute of Health). We compared single screenshots taken from video sequences of schooling A. katoptron without $(\mathrm{n}=37)$ and with illumination with red torches $(n=46)$. We defined relative length $(S L)$ of at least one individual as reference to estimate the relative distance between members of the school. We chose distances between individuals that seemed to be neighbors as two-dimensional recording could not provide a distinct spatial distribution (see also Fig. S4).

Blink frequencies were analyzed using the video analysis software Vidana 1.0. Specimens of A. katoptron were marked after the first occurrence in the video sequence and the behavior was analyzed until the specimen disappeared in the recording sequence. Exposure and Occlusion of light organs was analyzed frame by frame per individual occurrence. Mean values were summarized for all analyzed parameters. Blink frequencies were estimated based on pairs of light organ exposure and occlusion times. We created a Gaussian distribution (Fig. 4) using the internal SigmaPlot function (SigmaPlot 12.0) to show the distribution of blink frequencies during three situations in the field ("resting", "schooling" \& "avoidance"). Additionally, we created histograms with the internal Matlab function (Matlab R2015b). Here we chose a bin size of 0,6 Hz.

Statistical analysis. SigmaPlot 12.0 was used to evaluate statistical differences between test groups. Differences in blink frequencies, exposure and occlusion times of light organs, distance between individuals, swimming speed and spatial distribution were compared using a repeated measurement one-way ANOVA and HolmSidak post hoc analysis. All values are reported as mean \pm SEM (standard error of mean). Statistical significant values are reported as: ${ }^{\star} p \leq 0.05,{ }^{* *} p \leq 0.01 ;{ }^{\star * *} p \leq 0.001$. 


\section{References}

1. Haddock, S. H. D., Moline, M. A. \& Case, J. F. Bioluminescence in the sea. Annu. Rev. Mar. Sci. 2, 443-493. https://doi.org/10. 1146/annurev-marine-120308-081028 (2010).

2. Bessho-Uehara, M. et al. Kleptoprotein bioluminescence: parapriacanthus fish obtain luciferase from ostracod prey. Sci. Adv. 6, eaax4942. https://doi.org/10.1126/sciadv.aax4942 (2020).

3. Davis, M. P., Sparks, J. S. \& Smith, W. L. Repeated and widespread evolution of bioluminescence in marine fishes. PLoS ONE 11, e0155154. https://doi.org/10.1371/journal.pone.0155154 (2016).

4. Claes, J. M. \& Mallefet, J. Early development of bioluminescence suggests camouflage by counter-illumination in the velvet belly lantern shark Etmopterus spinax (Squaloidea: Etmopteridae). J. Fish Biol. 73, 1337-1350. https://doi.org/10.1111/j.1095-8649. 2008.02006.x (2008).

5. Harper, R. D. \& Case, J. F. Disruptive counterillumination and its anti-predatory value in the plainfish midshipman Porichthys notatus. Mar. Biol. 134, 529-540. https://doi.org/10.1007/s002270050568 (1999).

6. Herring, P. J. Sex with the lights on? A review of bioluminescent sexual dimorphism in the sea. J. Mar. Biol. Ass. 87, 829-842. https://doi.org/10.1017/S0025315407056433 (2007).

7. Widder, E. A. Bioluminescence in the ocean: origins of biological, chemical, and ecological diversity. Science (New York, NY) 328, 704-708. https://doi.org/10.1126/science.1174269 (2010).

8. Hellinger, J. et al. The flashlight fish anomalops katoptron uses bioluminescent light to detect prey in the dark. PLoS ONE 12, e170489. https://doi.org/10.1371/journal.pone.0170489 (2017).

9. Golani, D., Fricke, R. \& Appelbaum-Golani, B. Review of the genus Photoblepharon (Actinopterygii: Beryciformes: Anomalopidae). Acta Ichthyol. Piscat. 49, 33-41. https://doi.org/10.3750/AIEP/02530 (2019).

10. Ho, H.-C. \& Johnson, G. D. Protoblepharon mccoskeri, a new flashlight fish from eastern Taiwan (Teleostei: Anomalopidae). Zootaxa https://doi.org/10.11646/zootaxa.3479.1.5 (2012)

11. Morin, J. G. et al. Light for all reasons: versatility in the behavioral repertoire of the flashlight fish. Science 190, 74-76. https://doi. org/10.1126/science.190.4209.74 (1975).

12. Hellinger, J. et al. Analysis of the territorial aggressive behavior of the bioluminescent flashlight fish photoblepharon steinitzi in the Red Sea. Front. Mar. Sci. 7, 431. https://doi.org/10.3389/fmars.2020.00078 (2020).

13. Gruber, D. F. et al. Bioluminescent flashes drive nighttime schooling behavior and synchronized swimming dynamics in flashlight fish. PLoS ONE 14, e0219852. https://doi.org/10.1371/journal.pone.0219852 (2019).

14. Hendry, T. A., de Wet, J. R. \& Dunlap, P. V. Genomic signatures of obligate host dependence in the luminous bacterial symbiont of a vertebrate. Environ. Microbiol. 16, 2611-2622. https://doi.org/10.1111/1462-2920.12302 (2014).

15. Hendry, T. A., de Wet, J. R., Dougan, K. E. \& Dunlap, P. V. Genome evolution in the obligate but environmentally active luminous symbionts of flashlight fish. Genome Biol. Evol. 8, 2203-2213. https://doi.org/10.1093/gbe/evw161 (2016).

16. Haneda, Y. \& Tsuji, F. I. Light production in the luminous fishes Photoblepharon and Anomalops from the Banda Islands. Science (New York, NY) 173, 143-145. https://doi.org/10.1126/science.173.3992.143 (1971).

17. Bassot, J.-M. in Bioluminescence in Progress, edited by F. H. Johnson \& Y. Haneda (Princeton University Press1966), pp. 557-610.

18. Watson, M., Thurston, E. L. \& Nicol, J. A. C. Reflectors in the Light Organ of Anomalops (Anomalopidae, Teleostei). Proc. R. Soc. Lond. Ser. B Biol. Sci. 202, 339-351 (1978).

19. Mark, M. D. et al. Visual tuning in the flashlight fish Anomalops katoptron to detect blue, bioluminescent light. PLoS ONE 13, e0198765. https://doi.org/10.1371/journal.pone.0198765 (2018).

20. Howland, H. C., Murphy, C. J. \& McCosker, J. E. Detection of eyeshine by flashlight fishes of the family anomalopidae. Vis. Res. 32, 765-769. https://doi.org/10.1016/0042-6989(92)90191-K (1992).

21. McCosker, J. E. \& Rosenblatt, R. H. Notes on the biology, taxonomy, and distribution of flashlight fishes (Beryciformes: Anomalopidae). Jpn. J. Ich. 34, 157-164. https://doi.org/10.1007/BF02912410 (1987).

22. Parrish, J. K., Viscido, S. V. \& Grünbaum, D. Self-organized fish schools: an examination of emergent properties. Biol. Bull. 202, 296-305. https://doi.org/10.2307/1543482 (2002)

23. Pitcher, T. J. (ed.) Behaviour of Teleost Fishes (Chapman \& Hall, 1993).

24. Helfman, G. S., Collette, B. B., Facey, D. E. \& Bowen, B. W. The Diversity of Fishes. Biology, Evolution, and Ecology 2nd edn. (WileyBlackwell, Oxford, 2009).

25. McLean, S., Persson, A., Norin, T. \& Killen, S. S. Metabolic costs of feeding predictively alter the spatial distribution of individuals in fish schools. Curr. Biol. 28, 1144-1149. https://doi.org/10.1016/j.cub.2018.02.043 (2018).

26. Pitcher, T. J., Magurran, A. E. \& Winfield, I. J. Fish in larger shoals find food faster. Behav. Ecol. Sociobiol. 10, 149-151. https://doi. org/10.1007/BF00300175 (1982).

27. Ioannou, C. C., Guttal, V. \& Couzin, I. D. Predatory fish select for coordinated collective motion in virtual prey. Science (New York, NY) 337, 1212-1215. https://doi.org/10.1126/science.1218919 (2012).

28. Turner, G. F. \& Pitcher, T. J. Attack abatement: a model for group protection by combined avoidance and dilution. Am. Nat. 128, 228-240. https://doi.org/10.1086/284556 (1986).

29. Landeau, L. \& Terborgh, J. Oddity and the 'confusion effect' in predation. Anim. Behav. 34, 1372-1380. https://doi.org/10.1016/ S0003-3472(86)80208-1 (1986).

30. Kowalko, J. E. et al. Loss of schooling behavior in cavefish through sight-dependent and sight-independent mechanisms. Curr. Biol. 23, 1874-1883. https://doi.org/10.1016/j.cub.2013.07.056 (2013).

31. Partridge, B. L. \& Pitcher, T. J. The sensory basis of fish schools: Relative roles of lateral line and vision. J. Comp. Physiol. 135, 315-325. https://doi.org/10.1007/BF00657647 (1980).

32. Herbert-Read, J. E. et al. How predation shapes the social interaction rules of shoaling fish. Proc. Biol. Sci. https://doi.org/10.1098/ rspb.2017.1126 (2017).

33. Bierbach, D. et al. Using a robotic fish to investigate individual differences in social responsiveness in the guppy. $R$. Soc. Open Sci. 5, 181026. https://doi.org/10.1098/rsos.181026 (2018).

34. Berdahl, A., Torney, C. J., Ioannou, C. C., Faria, J. J. \& Couzin, I. D. Emergent sensing of complex environments by mobile animal groups. Science (New York, NY) 339, 574-576. https://doi.org/10.1126/science.1225883(2013) (2013).

35. Sosna, M. M. G. et al. Individual and collective encoding of risk in animal groups. Proc. Natl. Acad. Sci. USA 116, $20556-20561$. https://doi.org/10.1073/pnas.1905585116 (2019).

36. Kunz, H. \& Hemelrijk, C. K. Artificial fish schools: collective effects of school size, body size, and body form. Artif. Life 9, $237-253$. https://doi.org/10.1162/106454603322392451 (2003).

37. Worm, M. et al. Evidence for mutual allocation of social attention through interactive signaling in a mormyrid weakly electric fish. Proc. Natl. Acad. Sci. USA 115, 6852-6857. https://doi.org/10.1073/pnas.1801283115 (2018).

38. Marras, S., Batty, R. S. \& Domenici, P. Information transfer and antipredator maneuvers in schooling herring. Adapt. Behav. 20, 44-56. https://doi.org/10.1177/1059712311426799 (2012).

39. Cohen, A. C. \& Morin, J. G. It's all about sex: bioluminescent courtship displays, morphological variation and sexual selection in two new genera of caribbean ostracodes. J. Crustacean Biol. 30, 56-67. https://doi.org/10.1651/09-3170.1 (2010).

40. Rivers, T. J. \& Morin, J. G. Complex sexual courtship displays by luminescent male marine ostracods. J. Exp. Biol. 211, $2252-2262$. https://doi.org/10.1242/jeb.011130 (2008). 
41. Widder, E. A., Latz, M. I., Herring, P. J. \& Case, J. F. Far red bioluminescence from two deep-sea fishes. Science (New York, NY) 225, 512-514. https://doi.org/10.1126/science.225.4661.512 (1984).

42. Mensinger, A. F. \& Case, J. F. Luminescent properties of deep sea fish. J. Exp. Mar. Biol. Ecol. 144, 1-15. https://doi.org/10.1016/ 0022-0981(90)90015-5(1990).

43. Sasaki, A. et al. Field evidence for bioluminescent signaling in the Pony Fish, Leiognathus elongatus. Environ. Biol. Fishes 66, 307-311. https://doi.org/10.1023/A:1023959123422 (2003).

44. McFall-Ngai, M. J. \& Dunlap, P. V. Three new modes of luminescence in the leiognathid fish Gazza minuta: discrete projected luminescence, ventral body flash, and buccal luminescence. Mar. Biol. 73, 227-237. https://doi.org/10.1007/BF00392247 (1983).

45. Johnson, G. D. \& Rosenblatt, R. H. Mechanisms of light organ occlusion in flashlight fishes, family Anomalopidae (Teleostei: Beryciformes), and the evolution of the group. Zool. J. Linnean Soc. 94, 65-96. https://doi.org/10.1111/j.1096-3642.1988.tb008 82.x (1988).

46. Herbert-Read, J. E. et al. Inferring the rules of interaction of shoaling fish. Proc. Natl. Acad. Sci. USA 108, 18726-18731. https:// doi.org/10.1073/pnas.1109355108 (2011).

47. Siebeck, U. E., Parker, A. N., Sprenger, D., Mäthger, L. M. \& Wallis, G. A species of reef fish that uses ultraviolet patterns for covert face recognition. Curr. Biol. CB 20, 407-410. https://doi.org/10.1016/j.cub.2009.12.047 (2010).

48. Larsch, J. \& Baier, H. Biological Motion as an Innate Perceptual Mechanism Driving Social Affiliation. Curr. Biol. 28, 3523-3532. e4. https://doi.org/10.1016/j.cub.2018.09.014 (2018).

49. Kasumyan, A. O. Acoustic signaling in fish. J. Ichthyol. 49, 963-1020. https://doi.org/10.1134/S0032945209110010 (2009).

50. Santon, M. et al. Redirection of ambient light improves predator detection in a diurnal fish. Proc. Biol. Sci. 287, 20192292. https:// doi.org/10.1098/rspb.2019.2292 (2020).

51. de Busserolles, F., Fogg, L., Cortesi, F. \& Marshall, J. The exceptional diversity of visual adaptations in deep-sea teleost fishes. Semin. Cell Dev. Biol. https://doi.org/10.1016/j.semcdb.2020.05.027 (2020).

52. Bainbridge, R. The speed of swimming of fish as related to size and to the frequency and amplitude of the tail beat. J. Exp. Biol. 35 , 109 (1958)

53. Videler, J. J. \& Wardle, C. S. Fish swimming stride by stride: speed limits and endurance. Rev. Fish. Biol. Fish. 1, 23-40. https://doi. org/10.1007/BF00042660 (1991).

54. Ware, D. M. Bioenergetics of pelagic fish: theoretical change in swimming speed and ration with body size. J. Fish. Res. Bd. Can. 35, 220-228. https://doi.org/10.1139/f78-036 (1978).

55. Meyer-Rochow, V. B. Loss of bioluminescence inAnomalops katoptron due to starvation. Experientia 32, 1175-1176. https://doi. org/10.1007/BF01927610 (1976).

56. Barber, I., Downey, L. C. \& Braithwaite, V. A. Parasitism, oddity and the mechanism of shoal choice. J. Fish Biol. 53, 1365-1368. https://doi.org/10.1111/j.1095-8649.1998.tb00256.x (1998).

57. Ward, A. J. W., Duff, A. J., Krause, J. \& Barber, I. Shoaling behaviour of sticklebacks infected with the microsporidian parasite, Glugea anomala. Environ. Biol. Fish. 72, 155-160. https://doi.org/10.1007/s10641-004-9078-1 (2005).

58. Theodorakis, C. W. Size segregation and the effects of oddity on predation risk in minnow schools. Anim. Behav. 38, 496-502. https://doi.org/10.1016/S0003-3472(89)80042-9 (1989).

59. Steche, O. Die Leuchtorgane von Anomalops katoptron und Photoblepharon palpebratus, zwei Oberflächenfischen aus dem malayischen Archipel: Ein Beitrag zur Anatomie und Physiologie der Leuchtorgane der Fische (Z Wiss Zool., 1909).

60. Parrish, J. K. \& Edelstein-Keshet, L. Complexity, pattern, and evolutionary trade-offs in animal aggregation. Science (New York, NY) 284, 99-101. https://doi.org/10.1126/science.284.5411.99 (1999).

61. Woodland, D. J., Cabanban, A. S., Taylor, V. M. \& Taylor, R. J. A synchronized rhythmic flashing light display by schooling Leiognathus splendens (Leiognathidae: Perciformes). Mar. Freshwater Res. 53, 159. https://doi.org/10.1071/MF01157 (2002).

\section{Author contributions}

P.J., S.H. \& J.H. designed the experiments and wrote the manuscript. P.J., L.W., R.S. \& M.M. performed and analyzed laboratory experiments. P.J., B.S., G.L. \& S.H. collected and analyzed field recordings. All authors reviewed the manuscript.

\section{Funding}

Open Access funding enabled and organized by Projekt DEAL. The present study was carried out in accordance with the European Communities Council Directive of 2010 (2010/63/ EU) for care of laboratory animals and approved by a local ethics committee (Bezirksamt Arnsberg). The study was supervised by the animal welfare commission of the Ruhr- University Bochum. All experiments have been performed and reported according to the ARRIVE guidelines (https://arriveguidelines.org). We acknowledge support by the Open Access Publication Funds of the Ruhr-Universität Bochum.

\section{Competing interests}

The authors declare no competing interests.

\section{Additional information}

Supplementary Information The online version contains supplementary material available at https://doi.org/ 10.1038/s41598-021-85770-w.

Correspondence and requests for materials should be addressed to S.H.

Reprints and permissions information is available at www.nature.com/reprints.

Publisher's note Springer Nature remains neutral with regard to jurisdictional claims in published maps and institutional affiliations. 
(c) (i) Open Access This article is licensed under a Creative Commons Attribution 4.0 International cc) License, which permits use, sharing, adaptation, distribution and reproduction in any medium or format, as long as you give appropriate credit to the original author(s) and the source, provide a link to the Creative Commons licence, and indicate if changes were made. The images or other third party material in this article are included in the article's Creative Commons licence, unless indicated otherwise in a credit line to the material. If material is not included in the article's Creative Commons licence and your intended use is not permitted by statutory regulation or exceeds the permitted use, you will need to obtain permission directly from the copyright holder. To view a copy of this licence, visit http://creativecommons.org/licenses/by/4.0/.

(C) The Author(s) 2021 